\title{
Acute cardiac disease in a patient with hyper-IgE syndrome
}

\author{
${ }^{1}$ Allergy/Immunology Section, Louisiana State University Health Sciences Center, Shreveport, Louisiana, USA \\ ${ }^{2}$ Cardiology Section, Louisiana State University Health Sciences Center, Shreveport, Louisiana, USA \\ ${ }^{3}$ Pediatrics Infectious Disease Section, Louisiana State University Health Sciences Center, Shreveport, Louisiana, USA
}

\section{KEY WORDS}

Hyper-IgE syndrome; Job's

syndrome; immunodeficiency;

myocarditis; cardiomyopathy

\section{Corresponding author}

Sami L. Bahna

Allergy \& Immunology Section,

Louisiana State University Health Sciences

Center

1501 Kings Highway,

Shreveport, Louisiana 71130-3932, USA

Phone: +13186757625

Fax: +13186758815

E-mail: sbahna@1suhsc.edu

\section{Doi}

10.23822/EurAnnACI.1764-1489.13

\begin{abstract}
Summary
We describe the case of a 24-year-old male with hyper-IgE syndrome (HIES) which was diagnosed at 4 years of age and died from a very rare cardiac complication. He had typical clinical and laboratory manifestations of HIES, including total serum IgE as high as >100,000 IU/ $m L$. Stem cell transplantation was not available. During the 20-year follow-up, he suffered numerous various infections of the skin and deep organs, partial lung resection, as well as multiple bone fractures. At age 24, he developed acute decompensated heart failure associated with elevated serum troponin I and brain natriuretic protein. Two-dimensional echocardiogram revealed global hypokinesis of the left ventricle with estimated ejection fraction 20-25\%, and catheterization revealed ectasia of multiple coronary arteries. Endomyocardial biopsy showed lymphocytic myocarditis, focal necrosis, mild fibrosis, and myxoid degeneration, but cultures were negative. The patient improved on corticosteroid therapy and was discharged on heart failure therapy and external defibrillator. Six weeks later, he developed supraventricular tachycardia and persistent global hypokinesis and was treated with amiodarone. A trial of intravenous immunoglobulin was initiated and was repeated as outpatient every four weeks for four times. However, his cardiac function did not improve and he developed severe hypotension and pulseless electrical activity arrest. Resuscitation was unsuccessful. To the best of our knowledge, this is the first reported case of HIES complicated with lymphocytic myocarditis. Both immunologists and cardiologists need to be aware of such a complication and practice caution in using immunosuppressants when the patient's immune status is markedly compromised.
\end{abstract}

\section{Introduction}

Immunodeficiency diseases are often complicated with a variety of comorbid conditions, mostly infections and less common hematologic disorders, autoimmune diseases, and malignancy, but rarely heart disease.

\section{Case report}

We describe the case of a 24-year-old male with hyper-IgE syndrome (HIES) diagnosed at 4 years of age, with documented mutation in signal transducer and activator of transcription 3 (STAT3). He had been closely followed for management of various infections and other complications (table 1). He had almost all typical manifestations of the disease (1) including total serum $\mathrm{IgE}$ as high as > 100,000 IU/mL, severe eczema, retention of primary teeth, recurrent Staphylococcal aureus and fungal skin infections, as well as the typical facial features including prominent forehead, deep set eyes, broad nasal bridge, wide nasal tip, and mild prognathism. Over the years, he suffered major complications including severe scoliosis, osteoporosis, multiple bone 
fractures, and chronic skin infection on the chest caused by $F u$ sarium falciforme resistant to multiple antifungals and requiring resection. He also had staphylococcal lung abscess that required partial resection of the left upper lobe.

At age 24, he developed fatigue, dyspnea on exertion, orthopnea, and mild right sided pleuritic chest pain. Upon admission to the hospital, his symptoms were compatible with acute decompensated heart failure. He had no recent viral illness or previous heart disease. Physical examination was notable for tachycardia (120-130 beats/min), tachypnea (18-27 breaths/min), elevated jugular venous pressure to the jaw angle, pulmonary crackles bilaterally, and S3 gallop.

Table 1 - Recent and past clinical course of our patient with hyper-IgE syndrome.

\begin{tabular}{|c|c|c|}
\hline Age (yr) & Clinical complication and/or infection(s) & Treatment \\
\hline \multirow[t]{2}{*}{24} & $\begin{array}{l}\text { Recurrence of chronic Staphylococcus aureus (MSSA) }{ }^{1} \text { and } \\
\text { Fusarium falciforme infections of the anterior chest wall } \\
\text { Fusarium septic elbow joint } \\
\text { Lymphocytic myocarditis }\end{array}$ & $\begin{array}{l}\text { Culture-directed antibiotics, prophylactic } \\
\text { voriconazole, trimethoprim-sulfamethoxazole } \\
\text { Irrigation, debridement } \\
\text { As in text }\end{array}$ \\
\hline & $\begin{array}{l}\text { Multiple abscesses of right axillae, Staphylococcus aureus } \\
\text { (MSSA) }\end{array}$ & Incision/drainage, culture-directed antibiotics \\
\hline \multirow[t]{2}{*}{23} & Recurrence of chronic fungal anterior chest wall wound & $\begin{array}{l}\text { Debridement/excision of anterior chest wall wound } \\
\text { with graft complicated by } S \text {. aureus (MSSA) } \\
\text { post-surgical wound infection }\end{array}$ \\
\hline & Abscess of right biceps, Staphylococcus aureus (MSSA) & Incision/drainage with culture-directed antibiotics \\
\hline \multirow[t]{5}{*}{20} & Multiple bilateral axillary abscesses & Vancomycin, lymphadenectomy \\
\hline & Left upper lobe lung abscess with empyema & \\
\hline & Left flank abscess & \\
\hline & Right supraclavicular lymphadenitis & \\
\hline & Giardia & Metronidazole \\
\hline \multirow[t]{2}{*}{19} & Vertebral osteomyelitis in T11 & Vancomycin \\
\hline & Staphylococcus aureus (MSSA) pneumonia & Nafcillin \\
\hline 17 & Pulmonary abscess & Left lung partial resection \\
\hline \multirow[t]{2}{*}{16} & Groin abscess & Incision and drainage \\
\hline & Neck abscess & Incision and drainage \\
\hline \multirow[t]{3}{*}{15} & $\begin{array}{l}\text { Chronic and recurrent Fusarium fungal infection of ante- } \\
\text { rior chest wall subcutaneous tissue }\end{array}$ & $\begin{array}{l}\text { Surgical excision and placement of fasciocutaneous } \\
\text { flap after proven resistance to multiple antifungals } \\
\text { including fluconazole, voriconazole, itraconazole, } \\
\text { terbinafine, amphotericin B, and posaconazole }\end{array}$ \\
\hline & Developed osteoporosis & $\begin{array}{l}\text { Bisphosphonates - later discontinued after develop- } \\
\text { ment of esophagitis }\end{array}$ \\
\hline & & Vitamin D and calcium supplementation \\
\hline 12 & $\begin{array}{l}\text { Sepsis and osteomyelitis of left neck of femur due to } \\
\text { Staphylococcus aureus (MRSA) }\end{array}$ & Culture-directed antibiotics \\
\hline $8-11$ & Recurrent fractures of radius and ribs & \\
\hline \multirow[t]{2}{*}{7} & Recurrent sinusitis & Sinus surgery \\
\hline & Recurrent otitis media & Multiple tympanostomy tube placements \\
\hline 6 & Pneumonia & Antibiotic therapy \\
\hline 4 & Pneumonia & Antibiotic therapy \\
\hline
\end{tabular}

${ }^{1}$ Methicillin sensitive $S$. aureus

${ }^{2}$ Methicillin resistant $S$. aureus 
Electrocardiogram showed sinus tachycardia with diffuse ST segment elevations. Laboratory findings included elevated serum troponin I at $6.3 \mathrm{ng} / \mathrm{mL}$ (normal $<0.05 \mathrm{ng} / \mathrm{mL}$ ) and brain natriuretic protein at $6353 \mathrm{pg} / \mathrm{mL}$ (normal $5-125 \mathrm{pg} /$ $\mathrm{mL}$ ). He had mild anemia with Hgb level $12.1 \mathrm{~g} / \mathrm{dL}$ (normal $12.5-16.3 \mathrm{~g} / \mathrm{dL}$ ), and elevated absolute eosinophil count of $1.43 \mathrm{~K} / \mu \mathrm{L}$ (normal $0-0.5 \mathrm{~K} / \mu \mathrm{L}$ ). His previous eosinophil levels during the past two years ranged from 0.29 to $1.53 \mathrm{~K} / \mu \mathrm{L}$ and mostly were less than $1.0 \mathrm{~K} / \mu \mathrm{L}$.

Two-dimensional echocardiogram revealed global hypokinesis of left ventricle with estimated ejection fraction $20-25 \%$. On day two of the hospital admission, he developed episodes of sinus node pauses and left heart catheterization revealed ectasia of multiple coronary arteries. To rule out giant cell myocarditis, endomyocardial biopsy of the right ventricle was performed. It showed lymphocytic myocarditis, eosinophils in some blood vessel walls, focal necrosis, mild fibrosis, and myxoid degeneration (figure 1). The biopsy cultures were negative. Laboratory evaluation did not reveal infectious etiology, including HSV, parvovirus, CMV, EBV, Borrelia, HIV, or hepatitis. Methylprednisolone $(1 \mathrm{mg} / \mathrm{kg}$ daily) was administered for two days followed by a 2-week prednisone taper. The patient improved and was given an external defibrillator (life vest) on discharge with plan to repeat echocardiogram after three months of heart failure therapy.

Six weeks after discharge, the patient was re-admitted due to lightheadedness and palpitations. He admitted poor compliance with wearing the cardiac monitor. Electrocardiogram was consistent with supraventricular tachycardia. Echocar-

Figure 1 - Histology specimen of biopsy from the endomyocardium of right ventricle demonstrating lymphocytic infiltrate within the myocyte fibers, focal necrosis, and myxoid degeneration.

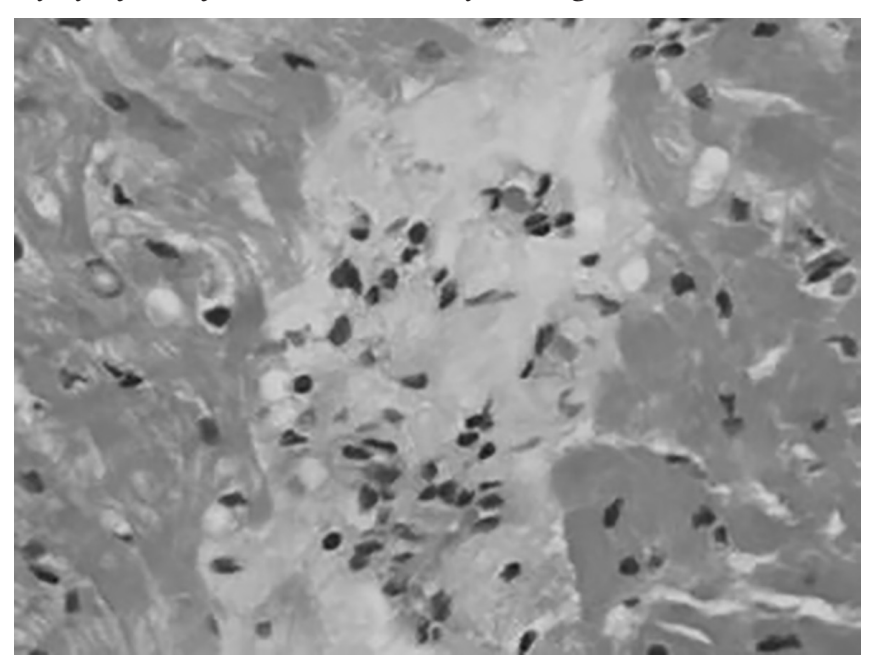

diogram showed persistent global hypokinesis without significant change from prior echocardiogram. He was treated with amiodarone. Because of a non-healing chest skin infection, placement of implantable cardioverter defibrillator was deferred. Further immunosuppressive agents were not considered due to his underlying immunocompromised state. A trial of intravenous immunoglobulin (IVIG) was initiated in a modest dose $(400 \mathrm{mg} / \mathrm{kg})$ because of the cardiac condition and was repeated as outpatient every four weeks for four times. However, his cardiac function did not improve and he had frequent hospital admissions for heart failure. Within 24 hours of his last admission, the patient became acutely dyspneic, cyanotic, and subsequently collapsed. He developed severe hypotension and pulseless electrical activity arrest. Bedside echocardiogram was negative for pericardial effusion. Resuscitation was attempted but all efforts were unsuccessful. The family did not consent for autopsy.

\section{Discussion}

Hyperimmunoglobulin E syndrome (HIES) is extremely rare with an estimated prevalence of 1 in 100,000 individuals (2). The condition was initially called "Job's syndrome," based upon a description of the biblical story on Job in the Old Testament "so went Satan forth from the presence of the Lord, and smote Job with sore boils from the sole of his foot unto his crown" (Job 2:7).

HIES can be autosomal dominant or autosomal recessive. The majority of patients have the autosomal dominant (AD-HIES) form with an underlying STAT3 gene defect $(3,4)$. In addition to eczema, AD-HIES is associated with high susceptibility to staphylococcal and fungal infections and defective dentition, skeletal, and connective tissues. The autosomal recessive form is not associated with skeletal or dental involvement but can have severe viral infections, marked eosinophilia, and severe neurologic complications (5).

In some patients, the connective tissue defect can lead to cardiac disease such as coronary arteries tortuosity, vascular ectasia, focal aneurysms, and pseudoaneurysms $(6,7)$. In animal experiments, cardiac myocyte-specific STAT3 deficiency in mice leads to cardiomyopathy with early cardiac failure (8). However, to the best of our knowledge, neither cardiomyopathy nor myocarditis has been reported in patients with HIES, except for a presumptive diagnosis of myocarditis in a 2-year-old child that was not specified by a biopsy (9). In our patient, lymphocytic myocarditis was biopsy-diagnosed and did not seem to be secondary to infection. The biopsy did not show significant eosinophils and the patient's circulating eosinophil count was not different from those during the previous years.

Initially, the cardiac dysfunction seemed to improve on corticosteroids in addition to appropriate treatment of heart 
failure including beta blockers, spironolactone, furosemide, ACE-inhibitors, and fluid restriction. Immunosuppressants were not considered because of their high risk in such patients. IVIG has been used, as an immunomodulatory therapy in a few scattered cases of acute myocarditis, presumably viral-induced, with good outcomes $(10,11,12)$. However, a recent Cochrane review concluded that more studies are needed before IVIG is routinely recommended for myocarditis (13). When our patient was readmitted, IVIG was administered in a modest dose $(400 \mathrm{mg} / \mathrm{kg})$ to avoid circulation overload on top of his heart failure. He showed some improvement that permitted his discharge from the hospital. It was repeated in the clinic every four weeks and he received a total of four doses. Unfortunately, his cardiac condition deteriorated and he died despite standard treatment of heart failure. Normally, transcription factor STAT1 has a proapoptotic effect and STAT3 has a protective effect on cardiac myocytes by antagonizing STAT1, and thus protecting against ischemia / reperfusion (14). Therefore, STAT3 mutation, as in our patient, could be a risk factor for myocarditis.

\section{Conclusions}

We report a biopsy-proven lymphocytic myocarditis as a complication of HIES in a young adult who was maintained in a relatively satisfactory clinical condition from early childhood in spite of multiple complications. Both immunologists and cardiologists should be aware of such a complication. Also, caution is required in considering the use of immunosuppressants when the immune status is markedly compromised. More data is needed on the dosage and potential benefit of using IVIG in myocarditis. To the best of our knowledge, this is the first reported case of HIES complicated with lymphocytic myocarditis.

\section{Acknowledgments}

The authors thank Dr. John Todd and Dr. Eric Wei as well as the numerous physicians who shared in the care of this patient over the years, particularly during his last months.

\section{References}

1. Buckley RH. The Hyper-IgE Syndrome. Clin Rev Allergy Immunol. 2001;20(1):139-54.

2. Mogensen TH. STAT3 and the Hyper-IgE syndrome: Clinical presentation, genetic origin, pathogenesis, novel findings and remaining uncertainties. JAK-STAT. 2013;2(2):e23435.

3. Minegishi Y, Saito M, Tsuchiya S, Tsuge I, Takada H, et al. Dominant-negative mutations in the DNA-binding domain of STAT3 cause hyper-IgE syndrome. Nature. 2007;448:1058-62.

4. Holland SM, DeLeo FR, Elloumi HZ, Hsu AP, Uzel G, et al. STAT3 mutations in the hyper-IgE syndrome. N Engl J Med. 2007;357:1608-19.

5. Renner ED, Puck JM, Holland SM, Schmitt M, Weiss M, et al. Autosomal recessive hyperimmunoglobulin E syndrome: a distinct disease entity. J Pediatr. 2004;144:93-9.

6. Yavuz H, Chee R. A review on the vascular features of the hyperimmunoglobulin E syndrome. Clin Exp Immunol. 2010;159(3):238-44.

7. Gharib AM, Pettigrew RI, Elagha A, Hsu A, Welch P, et al. Coronary abnormalities in hyper-IgE recurrent infection syndrome: depiction at coronary MDCT angiography. AJR Am J Roentgenol. 2009;193(6):W478-W481.

8. Hilfiker-Kleiner D, Hilfiker A, Fuchs M, Kaminski K, Schaefer A, et al. Signal transducer and activator of transcription 3 is required for myocardial capillary growth, control of interstitial matrix deposition, and heart protection from ischemic injury. Circ Res. 2004;95:187-95.

9. el Noor IB, Venugopalan P, Johnston WJ, and Froude JR. Ventricular aneurysm and myocarditis in a child with the hyperimmunoglobulin E syndrome. Eur Heart J. 1995;16(5):714-15.

10. Ozyiğit T, Unal Z, Ozben B. Successful intravenous immunoglobulin therapy in a case of acute fulminant myocarditis. Arch Turk Soc Cardiol. 2011;39(1):59-63.

11. Fairley SL, Herron B, Wilson CM, Roberts MJD. Acute fulminant necrotising lymphocytic myocarditis in a patient with mixed connective tissue disease: a rapid clinical response to immunosuppression. Ulster Med J.2014;83(2):119-20.

12. Kato S, Morimoto S, Hiramitsu S, Uemura A, Ohtsuki M, et al. Successful high-dose intravenous immunoglobulin therapy for a patient with fulminant myocarditis. Heart Vessels. 2007;22:48-51.

13. Robinson J, Hartling L, Vandermeer B, Klassen TP. Intravenous immunoglobulin for presumed viral myocarditis in children and adults. Cochrane Database of Systematic Reviews 2015, Issue 5. Art. No.: CD004370. DOI: 10.1002/14651858.CD004370.pub3.

14. Scarabelli, TM, Townsend PA, Chen Scarabelli C, Yuan Z, McCauley RB, et al. Amino acid supplementation differentially modulates STAT1 and STAT3 activation in the myocardium exposed to ischemia/reperfusion injury. Am J Cardiol. 2008;101(11):S63-S68. 